University of Nebraska - Lincoln

DigitalCommons@University of Nebraska - Lincoln

USDA National Wildlife Research Center - Staff Publications
U.S. Department of Agriculture: Animal and Plant Health Inspection Service

2012

\title{
Oblique color vision in an open-habitat bird: spectral sensitivity, photoreceptor distribution and behavioral implications
}

\author{
Bret A. Moore \\ Purdue University, bamoore@purdue.edu \\ Patrice Baumhardt \\ Purdue University \\ Megan Doppler \\ Purdue University \\ Jacquelyn Randolet \\ Purdue University \\ Bradley F. Blackwell \\ United States Department of Agriculture, bradley.f.blackwell@aphis.usda.gov \\ See next page for additional authors
}

Follow this and additional works at: https://digitalcommons.unl.edu/icwdm_usdanwrc

Moore, Bret A.; Baumhardt, Patrice; Doppler, Megan; Randolet, Jacquelyn; Blackwell, Bradley F.; DeVault, Travis L.; Loew, Ellis R.; and Fernández-Juricic, Esteban, "Oblique color vision in an open-habitat bird: spectral sensitivity, photoreceptor distribution and behavioral implications" (2012). USDA National Wildlife Research Center - Staff Publications. 1170.

https://digitalcommons.unl.edu/icwdm_usdanwrc/1170

This Article is brought to you for free and open access by the U.S. Department of Agriculture: Animal and Plant Health Inspection Service at DigitalCommons@University of Nebraska - Lincoln. It has been accepted for inclusion in USDA National Wildlife Research Center - Staff Publications by an authorized administrator of DigitalCommons@University of Nebraska - Lincoln. 


\section{Authors}

Bret A. Moore, Patrice Baumhardt, Megan Doppler, Jacquelyn Randolet, Bradley F. Blackwell, Travis L. DeVault, Ellis R. Loew, and Esteban Fernández-Juricic 
The Journal of Experimental Biology 215, 3442-3452 (c) 2012. Published by The Company of Biologists Ltd doi:10.1242/jeb.073957
This article is a U.S. government work, and is not subject to copyright in the United States.

RESEARCH ARTICLE

\title{
Oblique color vision in an open-habitat bird: spectral sensitivity, photoreceptor distribution and behavioral implications
}

\author{
Bret A. Moore ${ }^{1, \star}$, Patrice Baumhardt ${ }^{1, \star}$, Megan Doppler ${ }^{1}$, Jacquelyn Randolet ${ }^{1}$, Bradley F. Blackwell ${ }^{2}$, \\ Travis L. DeVault ${ }^{2}$, Ellis R. Loew ${ }^{3}$ and Esteban Fernández-Juricic ${ }^{1, \dagger}$ \\ ${ }^{1}$ Department of Biological Sciences, Purdue University, 915 West State Street, West Lafayette, IN 47907, USA, ${ }^{2}$ United States \\ Department of Agriculture, Animal and Plant Health Inspection Service, Wildlife Services, National Wildlife Research Center, Ohio \\ Field Station, Sandusky, OH 44870, USA and ${ }^{3}$ Department of Biomedical Sciences, Cornell University, Ithaca, NY 14853, USA \\ *These authors contributed equally to this work \\ ${ }^{\dagger}$ Author for correspondence (efernan@purdue.edu)
}

\begin{abstract}
SUMMARY
Color vision is not uniform across the retina because of differences in photoreceptor density and distribution. Retinal areas with a high density of cone photoreceptors may overlap with those with a high density of ganglion cells, increasing hue discrimination. However, there are some exceptions to this cell distribution pattern, particularly in species with horizontal visual streaks (bands of high ganglion cell density across the retina) that live in open habitats. We studied the spectral sensitivity and distribution of cone photoreceptors involved in chromatic and achromatic vision in the Canada goose (Branta canadiensis), which possesses an oblique rather than horizontal visual streak at the ganglion cell layer. Using microspectrophotometry, we found that the Canada goose has a violet-sensitive visual system with four visual pigments with absorbance peaks at $409,458,509$ and $580 \mathrm{~nm}$. The density of most cones involved in chromatic and achromatic vision peaked along a band across the retina that matched the oblique orientation of the visual streak. With the information on visual sensitivity, we calculated chromatic and achromatic contrasts of different goose plumage regions. The regions with the highest visual saliency (cheek, crown, neck and upper tail coverts) were the ones involved in visual displays to maintain flock cohesion. The Canada goose oblique visual streak is the retinal center for chromatic and achromatic vision, allowing individuals to sample the sky and the ground simultaneously or the horizon depending on head position. Overall, our results show that the Canada goose visual system has features that make it rather different from that of other vertebrates living in open habitats.
\end{abstract}

Key words: birds, color vision, visual ecology.

Received 15 April 2012; Accepted 26 June 2012

\section{INTRODUCTION}

The ability of animals to see colors depends on the availability of cone photoreceptors with different visual pigments (Land and Nilsson, 2002). Birds possess four spectral classes of visual pigment in their retinas associated with single cones (long wavelengthsensitive LWS cone, medium wavelength-sensitive MWS cone, short wavelength-sensitive SWS cone, and either a violet-sensitive VS cone or an ultraviolet-sensitive UVS cone), and thus they are tetrachromats (Hart, 2001a; Hunt et al., 2009). Birds also have double cones, associated with LWS visual pigments that are thought to be involved in the perception of achromatic signals, texture and motion (von Campenhausen and Kirschfeld, 1998; Osorio et al., 1999a; Osorio et al., 1999b; Goldsmith and Butler, 2005). Additionally, birds have five types of oil droplets (each associated with a given type of cone photoreceptor) that absorb light at certain wavelength ranges before passing it onto the photoreceptors (Goldsmith et al., 1984; Partridge, 1989; Hart, 2001b). Therefore, oil droplets enhance color discrimination by reducing the overlap in sensitivity between visual pigments (Hart and Hunt, 2007). Birds use this complex visual machinery for the perception of mating signals (e.g. Gomez and Théry, 2004), predators (e.g. Rubene et al., 2010), prey (e.g. Sandre et al., 2010) and conspecifics (e.g. Göth and Evans, 2004).
The ability to extract visual information is also dependent upon photoreceptor density and the connections between photoreceptors and retinal ganglion cells (which transfer the information to visual centers in the brain) through the retinal circuitry (e.g. bipolar cells, amacrine cells) (Dowling, 2012). When a large number of photoreceptors connect with a single ganglion cell, the signal has a high degree of summation (high convergence ratio), hence increasing retinal sensitivity at the expense of lowering resolution (Warrant, 1999). In contrast, when a lower number of photoreceptors connect with a single ganglion cell, the signal has a low degree of summation (low convergence ratio), reducing sensitivity. The latter scenario is generally associated with high ganglion cell density, leading to high visual resolution (i.e. detecting fine details of an object) (Warrant, 1999). The ratio between photoreceptors and retinal ganglion cells, or convergence ratio, has been used as an indirect indicator of spatial summation in the retinal circuitry (Boycott and Wässle, 1999; Querubin et al., 2009), which can vary in different parts of the retina (Shinozaki et al., 2010). The implication is that some regions of the retina have higher visual resolution than others, and the position of these retinal specializations is generally related to habitat complexity and the behavioral ecology of a species (Hughes, 1977; Collin, 1999). 
To increase resolution, the retinal area with the highest density of photoreceptors should overlap with the area of highest retinal ganglion cell density, hence keeping convergence ratios low. This is the case in some fish (Litherland and Collin, 2008), avian (Querubin et al., 2009) and mammalian (Ahnelt and Kolb, 2000) taxa. However, in some species there is a mismatch in the areas with high photoreceptor and high ganglion cell density (e.g. Calderone et al., 2003). This mismatch would indicate preferential sampling of specific information from some regions of the visual field outside of the main retinal specialization (Litherland and Collin, 2008). For instance, the medium/long wavelength-sensitive cones of sheep have higher densities along a band coincident with the distribution of retinal ganglion cells (Shinozaki et al., 2010). However, the short wavelengthsensitive cones have higher densities in the dorso-temporal region, which has been associated with higher color discrimination in the rostro-ventral part of the visual field that detects food and monitors the forward direction of locomotion (Shinozaki et al., 2010).

Comparatively little is known about the distribution of both photoreceptors and retinal ganglion cells in bird retinas. The only studies to date focus on species with a fovea (Querubin et al., 2009; Rahman et al., 2007a; Rahman et al., 2007b), which is a localized invagination of the retinal tissue (Meyer, 1977). However, no information, to our knowledge, is available on species with other types of retinal specializations, such as the visual streak, which consists of a high density band of ganglion cells across the retina (Meyer, 1977). Species with a visual streak are common in open areas [e.g. sooty shearwater (Puffinus griseus), great bustard (Otis tarda), great crested grebe (Podiceps cristatus) (Wood, 1917)]. The visual streak allows animals to obtain a panoramic and high resolution view of the horizon to enhance detection of predators, food and conspecifics (Hughes, 1977).

We studied the spectral sensitivity and distribution of cone photoreceptors involved in chromatic and achromatic vision in the Canada goose considering a previously published account of the distribution of its retinal ganglion cells (Fernández-Juricic et al., 2011). We conducted microspectrophotometry to measure the absorbance of the visual pigments and the oil droplets in the retina, and we mapped out variations in the density of different cone photoreceptors. The Canada goose is a good study species in which to establish the match in the distribution of photoreceptors and retinal ganglion cells because its visual streak is not horizontal as in most vertebrate species (parallel to the ground when the head is up), but oblique (Fernández-Juricic et al., 2011). This raises the question as to whether different cone photoreceptors would be specialized in sampling different regions of the visual field to compensate for the oblique placement of the visual streak in the ganglion cell layer. Additionally, the Canada goose is a highly social species that uses different visual displays for social communication (Mowbray et al., 2002), such as pair bonding (Akesson and Raveling, 1982), coordination of pre-flight movements (Raveling, 1969), and agonistic interactions (Raveling, 1970). We estimated the degree of visual saliency of different regions of its plumage to determine which areas may be used in social communication by using chromatic and achromatic contrast models (Vorobyev and Osorio, 1998; Endler and Mielke, 2005; Montgomerie, 2006) with information on the goose visual sensitivity. Our results have broad implications for understanding how the configuration of the sensory system shapes different behaviors (e.g. vigilance, food search, mate choice, etc.) (Collin, 1999; Fernández-Juricic, 2012).

\section{MATERIALS AND METHODS}

Canada geese Branta canadensis maxima were captured in Ohio in collaboration with the US Department of Agriculture, Animal and
Plant Health Inspection Service (Federal Permit MB019065-1, State Permit 11-299). We housed geese in a room with a $14 \mathrm{~h}: 10 \mathrm{~h}$ light-dark cycle, and provided them with water and cracked corn ad libitum. All animal housing, handling and experimental procedures were approved by the Purdue Animal Care and Use Committee protocol no. 09-018.

\section{Microspectrophotometry}

We used a total of 10 adult dark-adapted (2-6h) Canada geese for microspectrophotometry. After animals were euthanized, we immediately removed the eyes and measurements of the axial length (anterior portion of the cornea to the most posterior portion of the back of the eye, in $\mathrm{mm}$ ) were taken. We hemisected the eye with a razor blade to expose the inner eyecup containing the retina, removed the vitreous humor, and carefully extracted the retina following published techniques (Ullmann et al., 2012). We then removed a $\sim 3 \mathrm{~mm}^{2}$ fragment from a random location of the retina. This study was not designed to assess the pigment and oil droplet absorbance in different regions of the retina (e.g. dorsal versus ventral) because of sample size issues. We placed the retinal fragment on a $22 \times 30 \mathrm{~mm}$ glass slide, and macerated it with two razorblades. We added a drop of phosphate-buffered saline (PBS, $\mathrm{pH} 7.2-7.4)$ to the macerated retina and placed an $18 \mathrm{~mm}^{2}$ coverslip on top, and then sealed the preparation with black nail lacquer. We analyzed one to three $3 \mathrm{~mm}^{2}$ fragments per retina. We performed all these procedures either under infrared or dim red light to prevent bleaching of the visual pigments.

The absorbance of visual pigments and oil droplets was measured with a custom-made microspectrophotometer [see McFarland and Loew for a detailed description of the apparatus design (McFarland and Loew, 1994)]. A Zeiss Ultrafluar Glyc objective ( $\times 32$, NA 0.4) served as the condenser with a dry $(\times 80$, NA 0.9$)$ objective. An EXVision Super Circuits CCD camera was used to view the cells under an infrared LED lit background light on an 8 in TFT Color LCD Monitor covered with red Plexiglas. We estimated absorbance by measuring the number of photon counts, in $1 \mathrm{~nm}$ increments from 350 to $750 \mathrm{~nm}$, in an area with no cells (baseline measurement), followed by a measurement either inside the outer segment of a photoreceptor or inside an oil droplet (sample measurement) (Liebman, 1972). Absorbance, which is unit-less, was calculated by taking the logarithmic ratio of the baseline measurement to the sample measurement [MSP Control and Analysis Program (Loew and Stauble, 1988-1992)]. To verify the identity of the visual pigment, we bleached the outer segment for a minimum of $60 \mathrm{~s}$ and re-measured absorbance to confirm that the visual pigments were photolabile (Brown and Wald, 1964). The identity of oil droplets was verified from their spherical shape (Meyer et al., 1965), high optical density (Lipetz, 1984) and characteristically shaped absorbance spectra (Hart and Vorobyev, 2005).

We analyzed spectra that met criteria defined previously (Levine and MacNichol, 1985). We first determined the wavelength-specific peak sensitivity of the visual pigments $\left(\lambda_{\max }\right)$. We normalized and smoothed the visual pigment absorbance spectra, and fitted them to A1-rhodopsin templates using the MSP Control and Analysis program (Loew and Stauble, 1988-1992). In one visual pigment measurement, we could not open the data file with this program; thus, we used Microsoft Excel 2007 to determine the $\lambda_{\max }$ value of that pigment following two steps. First, we normalized the absorbance spectrum to 1 . Second, we fitted a series of A1rhodopsin templates, created from Govardovskii et al. (Govardovskii et al., 2000), to the normalized absorbance spectrum based on the $\lambda_{\max }$ value and the spread of the curve. The nomenclature used to 
classify the VS and SWS peak absorbance followed Hart (Hart, 2002) because genetic data to discriminate between SWS1 and SWS2 pigments were not available.

Oil droplet types can be characterized by determining regions of the oil droplet absorbance spectra where the absorbance rapidly decreases before reaching the visual pigment (Lipetz, 1984). Three parameters are commonly used to characterize oil droplet absorbance: $\lambda_{\text {mid, }}$ the wavelength at which half of the light is being absorbed by the oil droplet; $\lambda_{\text {cut }}$, the wavelength below which all light is absorbed by the oil droplet; and $\lambda_{0}$, the wavelength at which the oil droplet absorbs $63 \%$ of the light (or the wavelength when transmittance $=1 / e$ ) (Lipetz, 1984; Hart and Vorobyev, 2005). To determine these parameters, we first normalized the absorbance spectra to 1 . We calculated $\lambda_{\text {mid }}$ by determining the wavelength at which absorbance is half the peak absorbance of the entire spectrum ( 0.5 absorbance) (Lipetz, 1984; Hart and Vorobyev, 2005). We calculated $\lambda_{\text {cut }}$ by fitting a trend line to the $\lambda_{\text {mid }}$ point of the spectrum spanning $10 \mathrm{~nm}$ to either side of the $\lambda_{\text {mid }}$ point. Using a linear equation based on the trend line (absorbance $=a+b \times$ wavelength, where $b$ is the slope of the trend line), we then calculated $\lambda_{\text {cut }}$ by solving the equation for wavelength when absorbance $=1$ (Lipetz, 1984). Because of the spectral noise in the oil droplet measurements, we did not include in the analysis spectra where the $R^{2}$ value of the trend line was less than 0.4 .

$\lambda_{0}$ is an inherent property of a transmittance curve; consequently, we determined $\lambda_{0}$ mathematically from equations derived in Hart and Vorobyev (Hart and Vorobyev, 2005) as we measured the absorbance of oil droplets. We calculated $\lambda_{0}$ from the individual absorbance spectra as:

$$
\lambda_{0}=\lambda_{\text {cut }}+0.37 / B_{\text {mid }},
$$

where:

$$
B_{\text {mid }}=0.5 /\left(\lambda_{\text {mid }}-\lambda_{\text {cut }}\right)
$$

(Hart and Vorobyev, 2005). $B_{\text {mid }}$ is the slope of the transmittance at $\lambda_{\text {mid. }}$. We also reported $b$, the slope parameter that describes the rate of decay in absorbance after $\lambda_{\text {cut }}$. This parameter $b$ was calculated as:

$$
b=2.89 \times B_{\text {mid }},
$$

following Hart and Vorobyev (Hart and Vorobyev, 2005).

\section{Photoreceptor density and distribution}

We used four retinas (three of them from three of the individuals used for microspectrophotometry) to estimate the variation in the density of different types of photoreceptors. Each avian cone type has an oil droplet associated with it. Different oil droplets (and thus cones) can be discriminated in fresh retinas using a combination of bright and fluorescent lights (Hart, 2001b). Single cones with UVS or VS visual pigments have transparent (T-type) oil droplets that do not absorb light in the visible range of the spectrum (Hart and Hunt, 2007). Single cones with a SWS visual pigment have colorless (C-type) oil droplets whose cut-off wavelength varies between species from 392 to $449 \mathrm{~nm}$ (Hart and Hunt, 2007). Single cones with a MWS visual pigment have yellow (Y-type) oil droplets whose cut-off wavelength varies from 490 to $516 \mathrm{~nm}$ depending on the species (Hart and Hunt, 2007). Finally, single cones with a LWS visual pigment have red (R-type) oil droplets whose cut-off wavelength varies in different species from 514 to $586 \mathrm{~nm}$ (Hart and Hunt, 2007). The double cones generally have a LWS visual pigment, with the principal member having a P-type oil droplet (cutoff wavelength varies from 407 to $489 \mathrm{~nm}$ between species) that can be distinguished in preparations from the other oil droplet types (see Appendix). We were not able to identify rod photoreceptors when mapping out the retina because it required the use of different methodological procedures (e.g. Müller and Peichl, 1989). We estimated the density of cone photoreceptors by counting the number of oil droplets across different parts of the retina.

After extracting the retina following a similar method to that described above (Ullmann et al., 2012), we removed as much choroid and pigmented epithelium as possible without damaging the retinal tissue. We then flipped the retina such that the photoreceptor side faced upwards and made radial cuts to flatten it. To prevent desiccation during the retinal extraction and inversion, the retina was frequently bathed in PBS. Once the retina was positioned on the slide, we inspected it under a microscope (Olympus BX51) at $\times 4$ power under the bright field. We traced the perimeter of the retina using Stereo Investigator (version 9.13; MBF Bioscience, Williston, VT, USA). We used the SRS Image Series Acquire module (using the fractionator approach) to systematically superimpose a grid onto the traced retina. We used a mean of $248 \pm 3.33$ grid sites per retina, but photoreceptor density could not be measured from all of them (see Results) because in some patches there was some pigmented epithelium remaining that could not be removed without damaging the retina.

A counting frame $(100 \times 100 \mu \mathrm{m})$ was positioned in the upper left-hand corner of each grid site. At each counting frame, we concentrated on the plane with the most oil droplets in focus. We used an Olympus S97809 microscope camera to take pictures of each counting frame at $\times 40$ magnification under both brightfield and epifluorescence lights (Osram mercury short arc bulb). These two light sources were necessary to distinguish the different oil droplet types because of their different light absorbance properties (see below). We captured these pictures using SnagIt (www.techsmith.com/snagit.html), and counted the oil droplets in each counting frame using ImageJ (http://rsbweb.nih.gov/ij/). We estimated the following parameters in StereoInvestigator: asf (the ratio of the counting frame area to the grid area) $=0.005 \pm 0.0005$, and tsf (the ratio of the height of the dissector to the mean measured tissue thickness) $=1$. We estimated $\Sigma Q^{-}$per retina (sum of the total number of oil droplets per type) as follows: R-type $=6000 \pm 90, \mathrm{Y}-$ type $=4000 \pm 404, \quad$ C-type $=3000 \pm 380, \quad$ P-type $=9000 \pm 1170, \quad \mathrm{~T}$ type $=1000 \pm 153$ and total oil droplets $=23000 \pm 2730$.

We followed Hart's (Hart, 2001b) criteria to distinguish the different oil droplets (see details in Appendix). Based on the counts, we estimated the density (number of oil droplets $\mathrm{mm}^{-2}$ ) of each type of oil droplet. We did not correct for tissue shrinkage because pictures were taken of fresh retinas. Following previous work (Stone, 1981; Ullmann et al., 2012), we made photoreceptor topographic maps reflecting the variation of different oil droplet densities across the retina. We plotted the cell density values on a map produced by StereoInvestigator using OpenOffice Draw (www.openoffice.org). Within a given cell density range, we interpolated the isodensity line from one or more adjacent density values (see Results). The isodensity lines were drawn by hand (see Stone, 1981; Ullmann et al., 2012). We present topographic maps for each photoreceptor type as well as all types together.

\section{Chromatic and achromatic contrasts}

We estimated chromatic (based on hues) and achromatic (based on brightness) contrasts to determine which regions of the Canada goose plumage are more visually salient from the perspective of conspecifics. We used Vorobyev and Osorio's physiological model for the visual contrast calculations (Vorobyev and Osorio, 1998). Parameters entered in this model included: irradiance (spectral properties of 
ambient light conditions), reflectance of different parts of the goose plumage, reflectance of the visual background around a particular plumage spot, the relative density of different goose photoreceptors, and the absorbance of the visual pigments and oil droplets estimated with microspectrophotometry (see above). The information obtained in this study allowed us to parameterize the visual contrast models with the specifics of the Canada goose visual system.

We measured irradiance and reflectance with a StellarNet EPP2000 portable spectroradiometer (StellarNet, Tampa, FL, USA). We obtained a generic measure of ambient light by measuring on a single day with sunlight and approximately $40 \%$ cloud cover. We measured irradiance every $0.5 \mathrm{~nm}$ (range $300-700 \mathrm{~nm}$ ) using a cosine-corrected sensor calibrated with a standardized light source in $\mathrm{W} \mathrm{m}^{-2}$. We later converted measurements into $\mu \mathrm{mol} \mathrm{m}{ }^{-2} \mathrm{~s}^{-1} \mathrm{~nm}^{-1}$ for visual contrast calculations. We positioned the irradiance probe $1.2 \mathrm{~m}$ above the ground, and took two measurements at each cardinal point (north, south, east, west), and above towards the sky. We averaged each pair of measurements and then the five sets together.

We measured plumage reflectance on three live Canada geese. Measurements were taken from 16 plumage regions (Fig. 1) every $0.5 \mathrm{~nm}$, from 300 to $700 \mathrm{~nm}$, using a tungsten krypton light and deuterium light source simultaneously and a micron fiber optic probe. We calibrated the spectrometer with dark (black lid of the standard) and light (97\% reflectance of white light) standards. The surface of the probe is angled at $45 \mathrm{deg}$, which we held parallel to the feather. Three measurements were taken of each plumage region per individual, totaling nine measurements per region, which were then averaged together. As a visual background of a given plumage region, we used the average reflectance measurements of the three plumage regions surrounding the plumage region of interest. For instance, with the cheek as the plumage region of interest, we used the averaged reflectance of the neck, crown and forehead (Fig. 1) as the reflectance of the background.

For our visual contrast calculations, we used the wavelengthspecific sensitivity of visual pigments $\left(\lambda_{\max }\right)$ and oil droplets $\left(\lambda_{\text {mid }}\right)$ of Canada geese described in the Results. Because we were not able to collect the absorbance of the C-type oil droplet (see Results), we used previously published values (Endler and Mielke, 2005) for the C-type oil droplet $\left(\lambda_{\text {mid }}=459 \mathrm{~nm}\right)$, corresponding to a VS visual system.

We then calculated the wavelength-specific capture probabilities, $C_{\mathrm{r}}(\lambda)$, for each single cone photoreceptor type as described elsewhere (Endler and Mielke, 2005):

$$
C_{\mathrm{r}}(\lambda)=9.52 \times 10^{-14} T_{\mathrm{e}}(\lambda) T_{\mathrm{or}}(\lambda)\left[1-10^{-0.225 G_{\mathrm{r}}(\lambda)}\right],
$$

where $T_{\mathrm{e}}(\lambda)$ is the transmission spectrum of the ocular media in the eye, $T_{\text {or }}(\lambda)$ is the transmission spectrum of each oil droplet type, and $G_{\mathrm{r}}(\lambda)$ is the visual pigment template for each photoreceptor. We then approximated the transmission spectrum of a typical bird ocular media, $T_{\mathrm{e}}(\lambda)$ (see Endler and Mielke, 2005):

$$
\begin{aligned}
T_{\mathrm{e}}(\lambda) & =\ln \left(8.928 \times 10^{-13} \lambda^{5}-2.595 \times 10^{-9} \lambda^{4}\right. \\
& +3.006 \times 10^{-6} \lambda^{3}-0.001736 \lambda^{2}+0.5013 \lambda-55.56 .
\end{aligned}
$$

We converted the absolute absorbance data of each oil droplet type to transmittance via the following equation: transmittance $=10^{- \text {absorbance }}$. For the oil droplet present in the SWS cone, we approximated the transmission spectrum as follows (see Endler and Mielke, 2005):

$$
T_{\text {or }}(\lambda)=\exp \left\{-\exp \left[-b\left(\lambda-\lambda_{0}\right)\right]\right\},
$$

where rate of decay $b=0.088$ and $\lambda_{0}=459$. We then calculated $G_{\mathrm{r}}(\lambda)$ by using the normalized absolute absorbance spectra from each goose cone outer segment that we measured. After calculating $C_{\mathrm{r}}(\lambda)$,
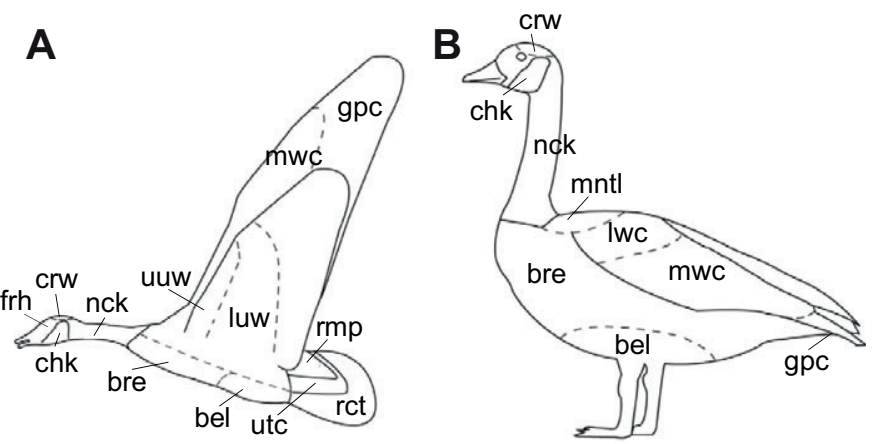

Fig. 1. Schematic representation of the Canada goose plumage regions in two body postures [(A) flying and $(B)$ on the ground] where reflectance was measured. bel, belly; bre, breast; chk, cheek; crw, crown; frh, forehead; gpc, greater primary covert; luw, lower under wing; Iwc, lesser wing covert; mntl, mantle; mwc, median wing covert; nck, neck; rct, rectrices; rmp, rump; utc, undertail coverts; uuw, upper under wing.

we normalized the resulting spectra and fitted them with templates to minimize the amount of noise in the spectra.

Chromatic and achromatic contrasts were calculated using Avicol v5 (Gomez, 2006). Vorobyev and Osorio's physiological color opponency model estimates the distance between the quantum catch of the stimuli/object and the background in a tetrahedral receptor colorspace. An individual is assumed to differentiate an object from the background when the distance between the two is greater than a threshold distance in colorspace, $\Delta S^{t}$ (Vorobyev and Osorio, 1998). Neural noise arising from the variability in processing at the receptor and subsequent neural stages sets the threshold distance (Vorobyev and Osorio, 1998). The threshold is estimated by incorporating the irradiance and reflectance measurements with the Canada goose visual properties into a calculation of the quantum catch for each photoreceptor $i\left(\Delta f_{i}\right)$ (Vorobyev and Osorio, 1998). The natural $\log$ ratio of $\Delta f_{i}$ for the object (A) and the background (B) were used as follows:

$$
\Delta f_{i}=\ln \left(\frac{Q_{i \mathrm{~A}}}{Q_{i \mathrm{~B}}}\right)=\ln \left(\frac{\int_{300}^{700} R_{\mathrm{A}}(\lambda) I(\lambda) S_{i}(\lambda) \mathrm{d} \lambda}{\int_{300}^{700} R_{\mathrm{B}}(\lambda) I(\lambda) S_{i}(\lambda) \mathrm{d} \lambda}\right),
$$

where $R_{\mathrm{A}}(\lambda)$ is the reflectance of the stimulus, $R_{\mathrm{B}}(\lambda)$ is the reflectance of the background, $I(\lambda)$ is the irradiance spectrum of the environment, $S_{i}(\lambda)$ is the spectral sensitivity of photoreceptor $i$, and $Q_{i}$ is the quantum catch for each photoreceptor $i$ for the object (A) and the background (B) (Gomez, 2006).

Based on the goose tetrachromatic visual system (see Results), we determined chromatic contrast $\left(\Delta S^{t}\right)$ (see Vorobyev and Osorio, 1998; Gomez, 2006) with the following equation:

$$
\begin{aligned}
\left(\Delta S^{t}\right)^{2} & \left.=\left(e_{1} e_{2}\right)^{2}\left(\Delta f_{4}-\Delta f_{3}\right)^{2}+\left(e_{1} e_{3}\right)^{2}\left(\Delta f_{4}-\Delta f_{2}\right)^{2}\right) \\
& +\left(e_{1} e_{4}\right)^{2}\left(\Delta f_{2}-\Delta f_{3}\right)^{2}+\left(e_{2} e_{3}\right)^{2}\left(\Delta f_{4}-\Delta f_{1}\right)^{2} \\
& \left.+\left(e_{2} e_{4}\right)^{2}\left(\Delta f_{3}-\Delta f_{1}\right)^{2}+\left(e_{3} e_{4}\right)^{2}\left(\Delta f_{2}-\Delta f_{1}\right)^{2}\right] /\left[\left(e_{1} e_{2} e_{3}\right)^{2}\right. \\
& \left.+\left(e_{1} e_{2} e_{4}\right)^{2}+\left(e_{1} e_{3} e_{4}\right)^{2}+\left(e_{2} e_{3} e_{4}\right)^{2}\right] .
\end{aligned}
$$

The neural noise from each photoreceptor was accounted for by the standard deviation of the noise in the receptor mechanism, $e_{i}$, independent of light intensity, and was calculated as:

$$
e_{i}=\omega / \sqrt{ } \eta_{i}
$$

where $\omega$ is the Weber fraction, and $\eta_{i}$ is the number of cells of type $i$ within the retinal integration area (Gomez, 2006; Vorobyev and Osorio, 1998). The Weber fraction was set to 0.05 following 
Gomez (Gomez, 2006). We then used the average density of oil droplets (number $\mathrm{mm}^{-2}$ ) associated with each type of photoreceptor to estimate the relative density of each photoreceptor type in relation to the VS cone. The resulting relative density values were used as the $\eta_{i}$ parameter in Eqn 9 for each cone type; VS=1, SWS cone $=10.93$, MWS cone $=12.46$ and LWS cone $=16.93$.

Achromatic contrast, $\Delta S_{Q}$, was calculated as follows:

$$
\Delta S_{Q}=\Delta f_{i} / e=\left|\ln \left(\frac{Q_{i \mathrm{~A}}}{Q_{i \mathrm{~B}}}\right)\right|=\left|\ln \left(\frac{\int_{300}^{700} R_{\mathrm{A}}(\lambda) I(\lambda) S_{i}(\lambda) \mathrm{d} \lambda}{\int_{300}^{700} R_{\mathrm{B}}(\lambda) I(\lambda) S_{i}(\lambda) \mathrm{d} \lambda}\right)\right| / e,
$$

where $S_{Q}$ is the spectral sensitivity of the photoreceptor involved in brightness detection, calculated in Avicol v5 by the summation of the MWS and LWS cone peak sensitivities (Gomez, 2006).

The differentiation between the object and the background in a tetrahedral colorspace is in units of just noticeable difference (JND). The threshold of discrimination (i.e. object is indistinguishable from the background) is when JND $<1$. JND values of 2-4 indicate that discrimination between the object and the background by the bird's visual system is difficult, but possible. $\mathrm{JND}>4$ indicates that an object can be readily discriminated from the background (Siddiqi et al., 2004).

\section{Statistical analysis}

We tested for differences in the density of single (combining VS, SWS, MWS, LWS) and double cones across the whole retina with an ANOVA test using the mean values of each individual goose.

To determine the degree to which our photoreceptor density data fit a horizontal or oblique orientation of the visual streak, we first measured the width of the visual streak found at the retinal ganglion cell layer (Fernández-Juricic et al., 2011). Using data from five individuals (Fernández-Juricic et al., 2011), we established that the proportional width of the visual streak at the ganglion cell layer was
$13.84 \%$ of the whole retina. We then used a layout of five sampling bands along the retina, each with the same proportional width as the visual streak: a central band, and two bands above and two below the central one. These bands had two orientations: horizontal (parallel to the ground) or oblique (following the inclination of the visual streak at the retinal ganglion cell layer: $30 \mathrm{deg}$ running from dorso-nasal to ventro-temporal) (Fernández-Juricic et al., 2011). We used general mixed linear models with the density of each single and double cone type as dependent variables. We included band as the independent factor, and used bird identity as the repeated measures factor as we included all values from the sampling grids for each individual. We ran models with horizontal and oblique band orientations and compared their fit to the data with AIC (lower values indicate a better fit). We also used the density (cells $\mathrm{mm}^{-2}$ ) of retinal ganglion cells in each band [data from Fernández-Juricic et al. (Fernández-Juricic et al., 2011)] and calculated the ratios of cone photoreceptors (single and double) to retinal ganglion cells. We acknowledge that these convergence ratios are coarse estimates as photoreceptor and ganglion cell density values came from different individuals; nevertheless, these ratios provide the first accounts of the variation in visual resolution across the goose retina.

\section{RESULTS \\ Microspectrophotometry}

We used 16 retinas (eye axial length $16.97 \pm 0.46 \mathrm{~mm}$ ) for microspectrophotometry. We obtained data on the spectral properties of the visual pigments from 49 cone outer segments and 33 rod outer segments from 6 birds (Table 1A). All cones were identified as having an A1-rhodopsin-shaped visual pigment. We found that the Canada goose has a VS visual system with four classes of single cone photoreceptors (Fig. 2A-D). The peak absorbance $\left(\lambda_{\max }\right)$ of the four cones and one rod visual pigments were as follows (see descriptive statistics in Table 1A): VS cone, $409 \mathrm{~nm}$; SWS cone, $458 \mathrm{~nm}$; MWS cone, $509 \mathrm{~nm}$; LWS cone, $580 \mathrm{~nm}$; and RH1 rod, $511 \mathrm{~nm}$ (Fig. 2A-E).

Table 1. Sensitivity of Canada goose visual pigments $(A)$ and cut-off wavelengths of oil droplets (B)

\begin{tabular}{|c|c|c|c|c|c|}
\hline \multicolumn{6}{|l|}{ A. Visual pigments } \\
\hline & Rod & VS single cone & SWS single cone & MWS single cone & LWS single cone \\
\hline Mean $\lambda_{\max }$ of spectra $(\mathrm{nm})$ & $511 \pm 0.8$ & 409 & $458 \pm 1.7$ & $509 \pm 1.0$ & 580 \\
\hline Number of outer segments & 33 & 2 & 6 & 40 & 1 \\
\hline \multicolumn{6}{|l|}{ B. Oil droplets } \\
\hline & T-Type & Y-Type & R-Type & P-Type & \\
\hline Mean $\lambda_{\text {mid }}(\mathrm{nm})$ & & $526 \pm 0.9$ & $598 \pm 0.7$ & $471 \pm 1.4$ & \\
\hline Mean $\lambda_{\text {cut }}(\mathrm{nm})$ & & $506 \pm 7.0$ & $559 \pm 15.2$ & $452 \pm 1.8$ & \\
\hline Mean $\lambda_{0}(\mathrm{~nm})$ & & $521 \pm 1.8$ & $588 \pm 4.1$ & $466 \pm 1.4$ & \\
\hline Mean $b$ & & $0.120 \pm 0.005$ & $0.087 \pm 0.004$ & $0.088 \pm 0.006$ & \\
\hline Mean $B_{\text {mid }}$ & & $0.042 \pm 0.002$ & $0.030 \pm 0.001$ & $0.031 \pm 0.002$ & \\
\hline \multicolumn{6}{|l|}{ Mean absorbance spectrum } \\
\hline$\lambda_{\text {mid }}(\mathrm{nm})$ & & 528 & 597 & 474 & \\
\hline$\lambda_{\text {cut }}(\mathrm{nm})$ & & 515 & 582 & 456 & \\
\hline$\lambda_{0}(\mathrm{~nm})$ & & 524 & 593 & 469 & \\
\hline$b$ & & 0.11 & 0.098 & 0.082 & \\
\hline$B_{\text {mid }}$ & & 0.039 & 0.034 & 0.029 & \\
\hline Number of oil droplets & 18 & 77 & 85 & 38 & \\
\hline
\end{tabular}

(A) Visual pigments: mean ( \pm s.e.m.) of the $\lambda_{\max }$ (peak absorbance) values of one rod and four single cone photoreceptors.

(B) Oil droplets: mean ( \pm s.e.m.) of $\lambda_{\text {mid }}$ (wavelength at which half-maximum light absorbance occurs), $\lambda_{\text {cut }}$ (wavelength at which maximum absorbance occurs), $\lambda_{0}$ (wavelength at which $63 \%$ absorbance occurs), $b$ (rate of decay in absorbance after $\lambda_{\text {cut }}$ ) and $B_{\text {mid }}$ (slope of the transmittance at $\lambda_{\text {mid }}$ ) (see Materials and methods for details) and the $\lambda_{\text {mid }}, \lambda_{\text {cut }}, \lambda_{0}, b$ and $B_{\text {mid }}$ calculated from the mean absorbance spectrum of each type of oil droplet.

VS, violet sensitive; SWS, short wavelength sensitive; MWS, medium wavelength sensitive; LWS, long wavelength sensitive.

The T-type oil droplet is associated with the VS single cone; the Y-type oil droplet is associated with the MWS single cone; the R-type oil droplet is associated with the LWS single cone; and the P-type oil droplet is associated with the double cone. We could not measure C-type oil droplets, associated with the SWS cone. 


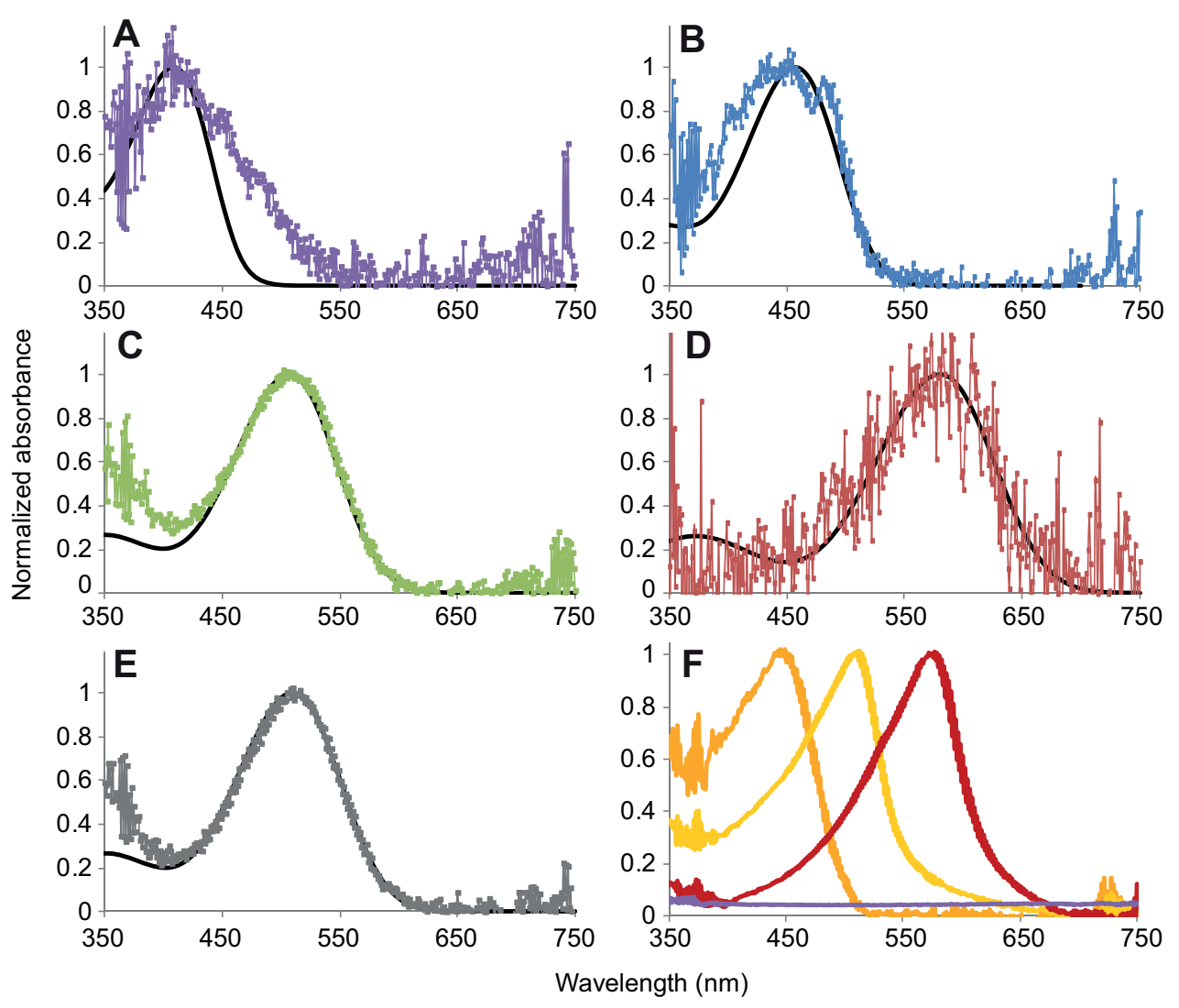

Fig. 2. Normalized absorbance spectra of Canada goose photoreceptors: $(A)$ violetsensitive VS cone, (B) short wavelengthsensitive SWS cone, (C) medium wavelength-sensitive MWS cone, (D) long wavelength-sensitive LWS cone, $(E)$ rod and $(F)$ oil droplets. In A-E, solid black lines represent the template made following Govardovskii et al. (Govardovskii et al., 2000), which had the same mean wavelength-specific peak sensitivity $\left(\lambda_{\max }\right)$ of the spectra for each visual pigment type. In $\mathrm{F}$, the orange line represents the P-type oil droplet; the yellow line, the Y-type oil droplet; the red line, the R-type oil droplet; and the purple line, the T-type oil droplet, which was not normalized to 1 for clarity.
We plotted the mean absorbance spectra of each visual pigment type (Fig. 2A-E) as well as the frequency distribution of the $\lambda_{\max }$ from the spectra used to create the means (Fig. 3A), and found that generally the peak sensitivity of the different visual pigments did not overlap. The one exception was the MWS and RH1 pigments, but we distinguished them based on morphological characteristics of their outer segments: the rod outer segment is longer, has more rectangular margins and more distinct striations than the MWS cone outer segment (Cohen, 1963). We detected some noise in the LWS pigment (Fig. 2D; Table 1) likely due to the low absorbance characteristic of this visual pigment and the low sample size $(N=1)$.

Four oil droplet types were identified in the goose retina by analyzing 218 oil droplets from 10 birds: T-type, P-type, Y-type and R-type (Fig. 2F, Fig.3B). We did not measure the T-type oil droplets because they do not absorb light in the $330-800 \mathrm{~nm}$ portion of the spectrum as they do not contain carotenoids (Bowmaker et al., 1997). We were not able to measure the absorbance of the oil droplet associated with the SWS cone (C-type). A potential reason for this might be that the C-type oil droplet $\lambda_{\text {mid }}$ and $\lambda_{\text {cut }}$ are difficult to distinguish from the P-type oil droplet, which occupies a similar part of the visual spectrum (i.e. $430-500 \mathrm{~nm}$, Fig. 3B) (Bowmaker et al., 1997; Hart and Hunt, 2007). We could not differentiate between the C-type and the P-type based on the attachment of the oil droplet to the outer segment because in our preparations we only found free-floating oil droplets.

Oil droplets act as long-pass cutoff light filters that shift the peak sensitivity of the photoreceptors (Bowmaker, 1977). The mean $\lambda_{\text {mid }}$ and $\lambda_{\text {cut }}$ parameters were determined for three of the four oil droplet types: P-type, 471, $452 \mathrm{~nm}$; Y-type, 526, 506 nm; and R-type, 598, $559 \mathrm{~nm}$, respectively (Table 1B, Fig. 2F). By calculating the wavelengths at which half-maximum absorbance $\left(\lambda_{\text {mid }}\right)$ and maximum absorbance $\left(\lambda_{\text {cut }}\right)$ occur, we could determine the effect of each oil droplet type on the peak sensitivity of each photoreceptor (Hart and Hunt, 2007). After considering the effects of the oil droplets, we found that the peak sensitivity of the VS, SWS, MWS and LWS cones shifted to $411,474,545$ and $618 \mathrm{~nm}$, respectively (Fig. 3C).

\section{Photoreceptor density and distribution}

We used four retinas from different individuals (eye axial length $=15.64 \pm 0.17 \mathrm{~mm}$ ) to map out the distribution of oil droplets. We were able to correctly identify and classify oil droplets from $241.25 \pm 3.35$ counting frames per individual.

The density of the different photoreceptors varied across the Canada goose retina. Single cones $\left(5896 \pm 548\right.$ oil droplets $\left.\mathrm{mm}^{-2}\right)$ had a significantly higher density than double cones ( $3732 \pm 548$ oil droplets $\left.\mathrm{mm}^{-2} ; F_{1,6}=7.78, P=0.032\right)$. Within single cones, the LWS cones were the most abundant (2447 \pm 341 R-type oil droplets $\left.\mathrm{mm}^{-2}\right)$ and VS cones were the least abundant (413 \pm 68 T-type oil droplets $\left.\mathrm{mm}^{-2}\right)$, with the MWS $\left(1728 \pm 142\right.$ Y-type oil droplets $\mathrm{mm}^{-2}$ ) and SWS (1307 \pm 140 C-type oil droplets $\mathrm{mm}^{-2}$ ) cones having intermediate values.

The topographic maps show that the retinal areas with the higher densities of photoreceptors followed a band-like shape across the retina (Fig. 4). This band-shaped area appeared to have a certain degree of inclination when considering specifically the MWS (Fig. 4C) and LWS (Fig. 4D) single cones, and double cones (Fig. 4E), as well as all single and double cones combined (Fig. 4F). However, this trend was visually less marked in the SWS (Fig. 4B) and VS (Fig. 4A) single cones.

We divided the retina into five bands following a horizontal orientation (parallel to the ground) or an oblique orientation (following the orientation of the visual streak in the retinal ganglion cell layer, Fig. 5). We found significant differences in cell density across bands in both orientations (Table 2); however, based on the 

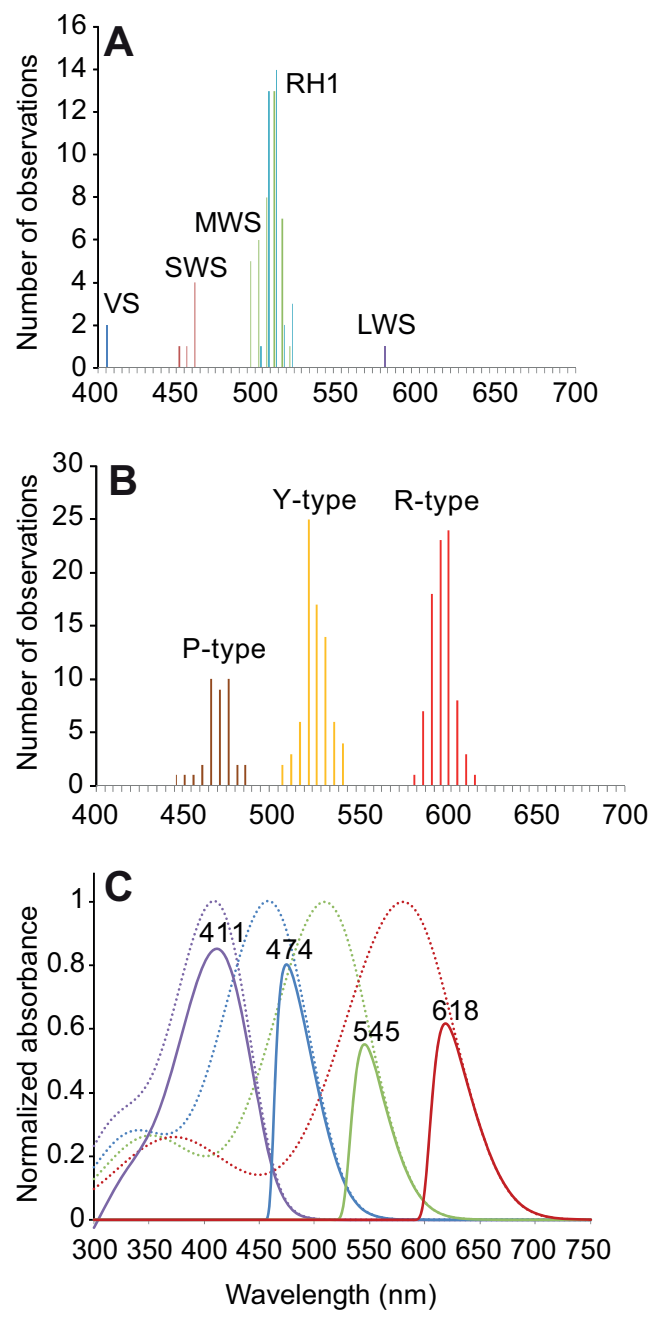

Fig. 3. (A) Histograms of $\lambda_{\max }$ values for each visual pigment type (VS, violet-sensitive cone; SWS, short wavelength-sensitive cone; MWS, medium wavelength-sensitive cone; LWS, long wavelength-sensitive cone; and $\mathrm{RH} 1$, rod) that were used to calculate the mean spectra for each visual pigment type (Fig. 2A-E). (B) Histograms of $\lambda_{\text {mid }}$ values (the wavelength at which half of the light is being absorbed) for each oil droplet type (P-type, Y-type and R-type) that were used to calculate the mean spectra (Fig. 2F). (C) Peak sensitivity of single cone photoreceptors in the Canada goose retina. Dotted lines represent the sensitivity curves of the visual pigments in the outer segment of each photoreceptor type. Solid lines represent the sensitivity curves of the entire photoreceptor, which includes the effects of the ocular media and oil droplets on the visual pigment sensitivity. The violet line represents the VS cone; the blue line, the SWS cone; the green line, the MWS cone; and the red line, the LWS cone.

AIC values, the oblique orientation had a better fit to the density of the different cone photoreceptors than the horizontal orientation (Table2). Based on the oblique orientation, the higher density of both single and double cones occurred along the visual streak and decreased significantly towards the dorso-temporal and ventro-nasal areas of the retina (Table2, Fig. 5). Finally, the ratio of photoreceptors (single and double cones) to retinal ganglion cells decreased from the periphery (around 5:1) towards the oblique visual streak (2:1; Fig. 5).

\section{Chromatic and achromatic contrasts}

We parameterized the visual contrast models with the information on the Canada goose visual system. We found that different parts of the Canada goose plumage had different degrees of visual saliency from the perspective of conspecifics (Table 3, Fig. 1). Based on chromatic contrast, the crown, neck and cheek contrasted the most against surrounding parts of the plumage (Table 3). Based on achromatic contrast, the cheek, upper tail covert and neck contrasted the most against surrounding parts of the plumage (Table 3 ).

\section{DISCUSSION}

Canada geese have a VS visual system as indicated by the presence of VS cones presumably expressing a SWS1 opsin, with the visual pigment peaking at $409 \mathrm{~nm}$. Consequently, the spectral range of its visual system does not reach the ultra-violet portion of the spectrum, as is the case for some other bird species (Hart and Hunt, 2007). Actually, other species from the same order Anseriformes have also been shown to have VS visual systems with peak sensitivities varying from 415 to $426 \mathrm{~nm}$ (Anas sp.) (Jane and Bowmaker, 1988). This suggests a certain degree of phylogenetic conservatism in this order based on the SWS1(VS) opsin, which is the ancestral state in birds (Ödeen and Håstad, 2003; Hunt et al., 2009), although recent evidence indicates that transitions between VS and UVS (and vice versa) are more common than previously expected (e.g. Passeriformes) (Ödeen et al., 2011). Additionally, the absorbance of the other Canada goose visual pigments (SWS, MWS, LWS) and oil droplets was within the range found in other avian orders (Hart and Hunt, 2007).

The overall distribution of single and double cone photoreceptors overlapped with the orientation of the visual streak found at the retinal ganglion cell layer (Fernández-Juricic et al., 2011). This matching was more pronounced for the MWS and LWS single cones and the double cones, but less pronounced for the SWS and VS single cones (Fig. 4). In the case of the SWS cones, the area with the highest density was more temporally placed, which would project towards the relatively wide binocular field of the Canada goose (Fernández-Juricic et al., 2011), possibly providing better discrimination in this region of the spectrum for social interactions or foraging opportunities. The distribution of VS single cones consisted of several high density spots that could be considered obliquely oriented. This spotty distribution may be the result of the proportionally low densities of VS cones in the retina, which has been reported in other species (Hart, 2001b), suggesting that the degree of spatial resolution in this portion of the spectrum may be relatively low.

The matching of the spatial distribution of photoreceptors and ganglion cells has been studied in three other bird species. In rock pigeons (Columba livia), the higher density of ganglion cells is matched by a higher density of cone photoreceptors in the fovea and the area dorsalis (e.g. a thickening of the retinal tissue) (Querubin et al., 2009). In the mallard (Anas platyrhynchos) and jungle crow (Corvus macrorhynchos), the highest density of cone photoreceptors was coincident with the highest density of ganglion cells towards the center of the retina (Rahman et al., 2007a; Rahman et al., 2007b). Overall, in the avian species studied to date, the overlay of photoreceptor and ganglion cell distribution is spatially coincident (see also Fite and Rosenfield-Wessels, 1975), even in species with an oblique visual streak like the Canada goose. In mammals, there is generally a match between the distribution of ganglion cells and the MWS/LWS cone; however, in some species there is a mismatch between ganglion cells and SWS cones (Wikler and Rakic, 1990; Ahnelt et al., 2006; Schiviz et al., 2008). In fish, areas of high density of ganglion cells and cone photoreceptors match even in species with more than one retinal specialization (e.g. two areae) (Litherland and Collin, 2008). The mismatch in some fish is between the spatial 

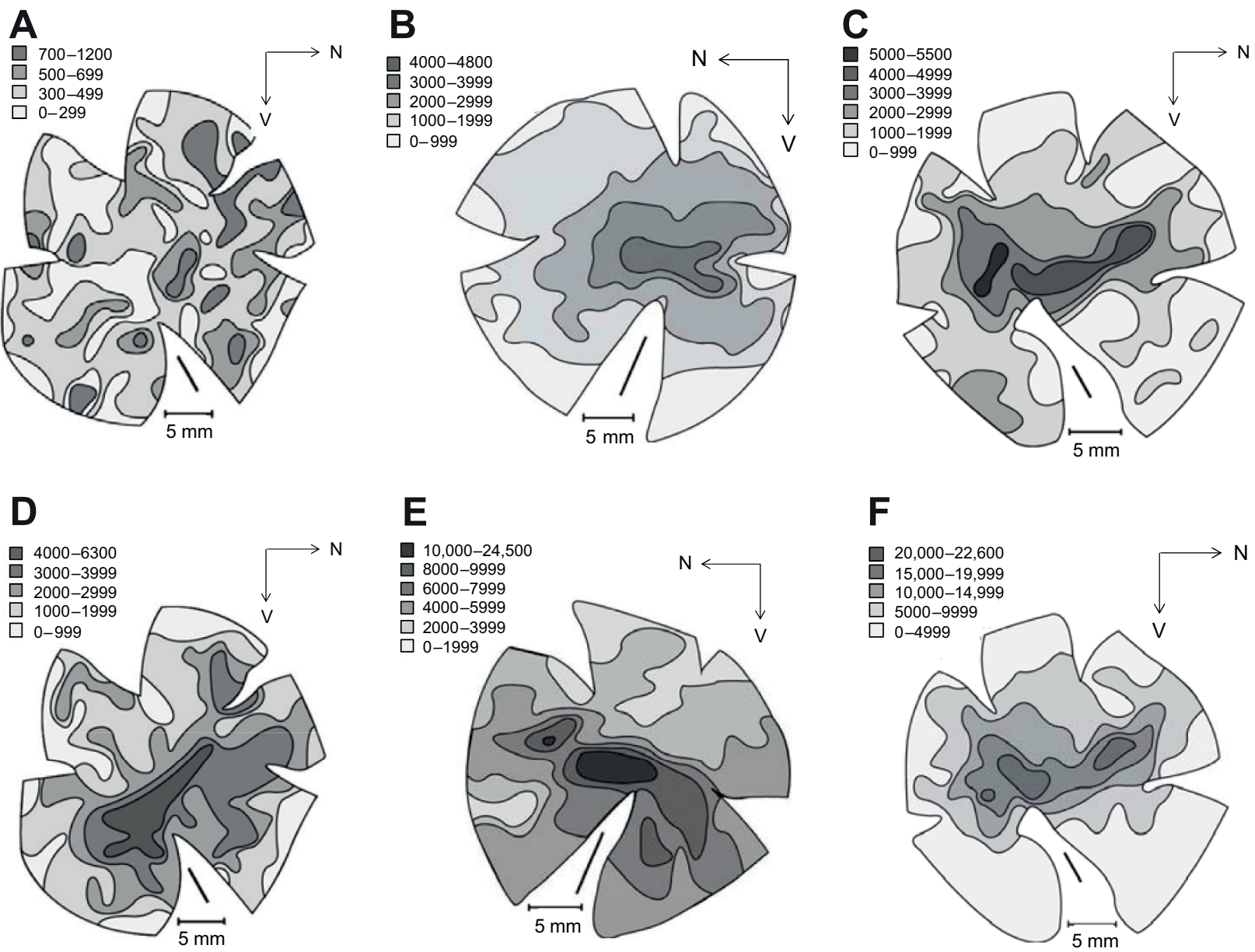

Fig. 4. Topographic maps representing the distribution of photoreceptors (using oil droplets as proxies) in the photoreceptor layer of the Canada goose retina: (A) VS single cones (T-type oil droplets); (B) SWS single cones (C-type oil droplets); (C) MWS single cones (Y-type oil droplets); (D) LWS single cones (R-type oil droplets); (E) double cones (P-type oil droplets); and ( $F$ ) all single and double cones together. The maps correspond to different individuals. Ranges represent the oil droplet density (number $\mathrm{mm}^{-2}$ ). N, Nasal; V, Ventral.

distribution of cone and rod photoreceptors, suggesting differential information sampling between photopic (i.e. under daylight conditions) and scotopic (i.e. under low light conditions) vision (Litherland and Collin, 2008).

An important implication of the matching of all cone photoreceptors to ganglion cells in the Canada goose is that the oblique visual streak is also the area with the highest chromatic (single cones) and achromatic (double cones) resolution. Our mapping results are supported by the reduction in the convergence ratios between photoreceptors and ganglion cells towards the visual streak (2:1). Similar convergence ratios have been found in the fovea of other bird species, such as pigeons (2.6:1) (Querubin et al., 2009), sparrow hawks Falco sparverius (2.8:1) and sunbirds Nectarina chalypea (2:1) (Fite and Rosenfield-Wessels, 1975). We did not study the distribution of rods in the retina, so our conclusions apply only to photopic vision. However, rods have been found in the peripheral areas of the avian retina at relatively low densities $(20 \%$ of the photoreceptors) (Querubin et al., 2009).

The oblique orientation of the Canada goose visual streak when the bill is parallel to the ground suggests that individuals can obtain high quality information from the upper part of the binocular field (above the plane of the bill) to the rear of the head in the lateral field (below the plane of the body). Therefore, geese would be able to 'see' the sky and the ground simultaneously with high visual

Table 2. Variation in the density of photoreceptors across five bands (oriented either horizontally or obliquely) in the retina

\begin{tabular}{lcccc}
\hline Cone type & AIC horizontal & $F_{4,12}(P$-values $)$ horizontal & AllC oblique & $F_{4,12}(P$-values $)$ oblique \\
\hline VS single cone & $11,608.8$ & $16.04(<0.001)$ & $11,483.2$ & $7.67(0.003)$ \\
SWS single cone & $12,988.9$ & $18.23(<0.001)$ & $12,831.7$ & $20.33(<0.001)$ \\
MWS single cone & $13,223.3$ & $14.60(<0.001)$ & $13,095.3$ & $16.85(<0.001)$ \\
LWS single cone & $13,629.0$ & $13.24(<0.001)$ & $13,429.4$ & $15.46(<0.001)$ \\
Double cone & $14,597.8$ & $19.46(<0.001)$ & $14,374.8$ & $27.11(<0.001)$ \\
\hline
\end{tabular}

We calculated Akaike information criterion (AIC) values to establish which distribution fitted the data better (lower AIC values indicate a better fit). 


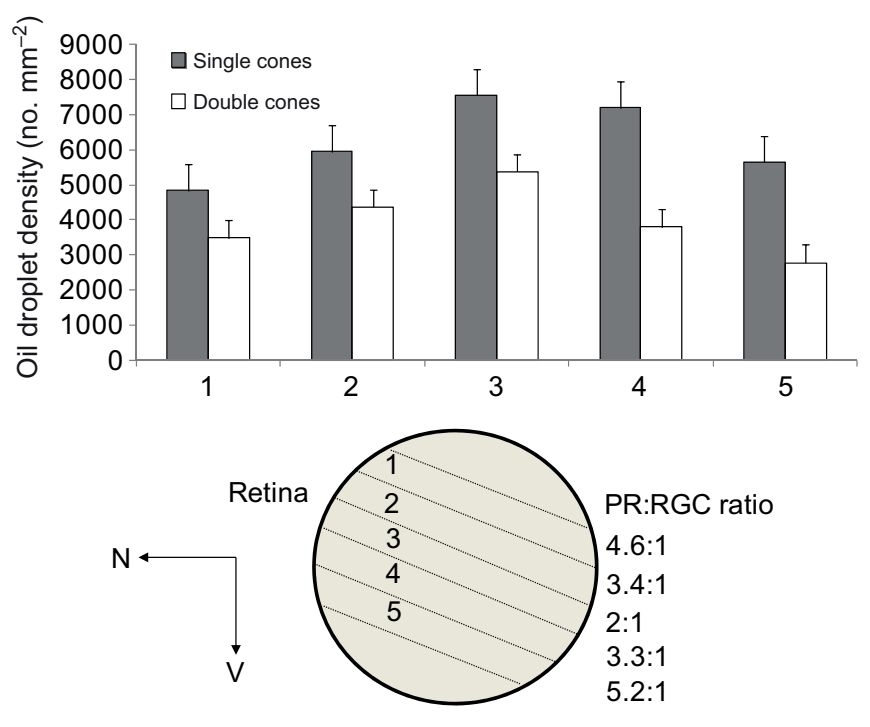

Fig. 5. Variation in the density of single and double cones (based on the density of oil droplets) in five different bands across the retina (1, dorsotemporal; 2, dorso-centro-temporal; 3, central; 4, ventro-centro-nasal; 5, ventro-nasal) aligned with the oblique orientation of the visual streak. The convergence ratio - the relative density the photoreceptors $(\mathrm{PR})$ to retinal ganglion cells (RGC) - is shown.

resolution, which would be advantageous for detecting predators, conspecifics and food in three dimensions (Fernández-Juricic et al., 2011). Interestingly, Canada geese also frequently tilt their bills downwards while their heads are up (Fernández-Juricic et al., 2011), which would align the visual streak with the horizon and provide the benefits of higher chromatic and achromatic vision along the transition line between the sky and the ground in the open habitats they commonly use (Mowbray et al., 2002).

We used the information on the goose visual sensitivity to determine the saliency from the visual perspective of conspecifics of different plumage regions that could be used in social communication.
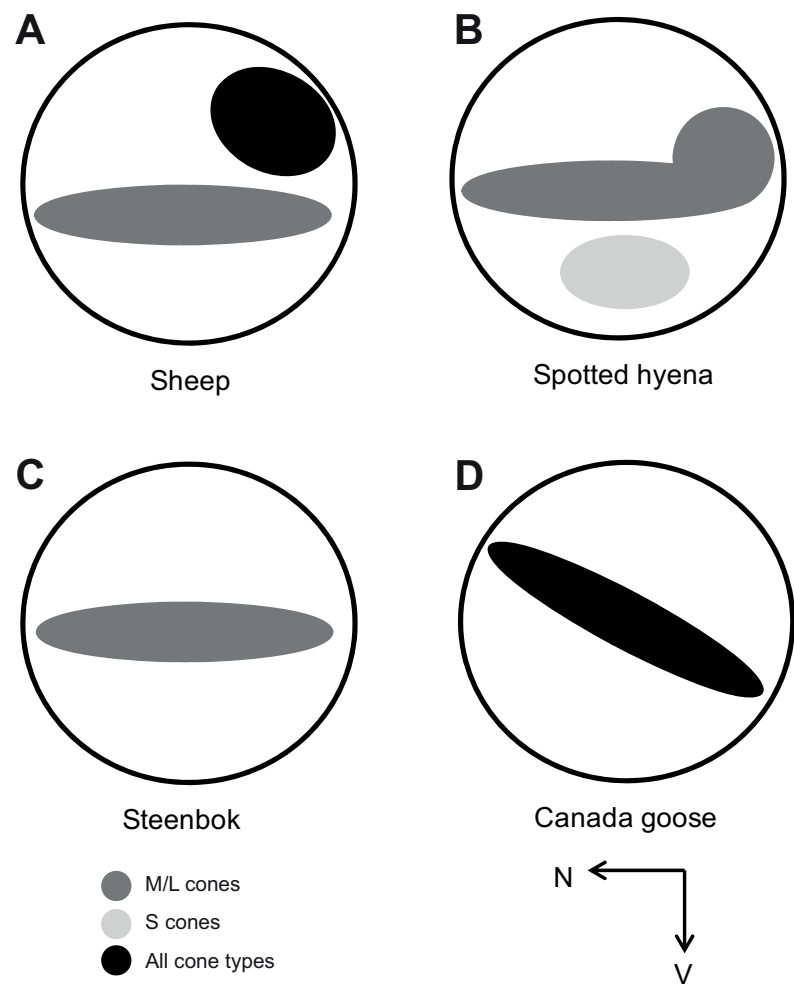

Fig. 6. Schematic examples of the distribution of different cone photoreceptors in four vertebrates that live in open areas and have visual streaks in their retinal ganglion cell layer. (A) The domestic sheep (Ovis aries) has a high density of MWS/LWS (M/L) cones along the horizontal visual streak as well as in the dorso-temporal part of the retina where it overlaps with the high density of SWS (S) cones (Shinozaki et al., 2010). (B) The spotted hyena (Crocuta crocuta) has an L-shaped visual streak (whose main axis is horizontal) with a high density of $\mathrm{M}$ cones, whereas the $\mathrm{S}$ cones are more abundant in the ventral part of the retina (Calderone et al., 2003). (C) The steenbok (Raphicerus campestris) has a well-defined horizontal visual streak with a high density of M cones (Schiviz et al., 2008). (D) The Canada goose five cone photoreceptor types (involved in chromatic and achromatic vision) have their highest density along the oblique visual streak. N, nasal; V, ventral.

Table 3. Chromatic and achromatic contrasts of different plumage regions from the perspective of a Canada goose

\begin{tabular}{lcccc}
\hline Plumage region & Abbreviation & Background region & Chromatic contrast & Achromatic contrast \\
\hline Belly & bel & bre & 2.07 & 7.87 \\
Belly while flushing & bel flsh & bre + luw + uuw & 3.09 & 2.98 \\
Breast & bre & bel + nck + lwc brown + lwc white & 2.54 & 25.15 \\
Breast while flushing & bre flsh & bel+ luw + uuw + nck & 1.69 & 20.55 \\
Cheek & chk & frh + crw + nck & 22.07 & 86.51 \\
Crown & crw & chk + frh + nck & 34.66 & 66.66 \\
Forehead & frh & crw + chk + nck & 8.65 & 59.11 \\
Greater primary covert & gpc & mwc & 7.45 & 11.70 \\
Lower under wing & luw & bre + bel + uuw & 4.44 & 21.35 \\
Lesser wing covert - brown & Iwc brown & Iwc white + mwc + mntl & 4.96 & 5.60 \\
Lesser wing covert - white & Iwc white & Iwc brown + mwc + mntl & 1.50 & 8.58 \\
Mantle & mntl & nck + lwc brown + lwc white & 1.79 & 0.82 \\
Median wing covert & mwc & Iwc white + lwc brown + gpc & 31.94 & 0.61 \\
Neck & nck & crw + mntl + bre & 4.53 & 68.01 \\
Rectrices & rct & gpc + utc & 6.46 & 55.09 \\
Rump & rmp & gpc + utc & 5.79 & 58.74 \\
Upper tail covert & utc & rrct + rmp & 2.71 & 5.38 \\
Upper under wing & uuw & bre + bel + luw & \\
\hline
\end{tabular}

Contrasts are measured in units of just noticeable difference (JND) (see Materials and methods for details). Lesser wing covert (Iwc) - brown and white refer to different color patches on feathers in the Iwc plumage region. Refer to Fig. 1 for the topographic representation of plumage regions that were measured on the goose. 
Table A1. Criteria used to distinguish different types of oil droplets in the Canada goose retina (modified from Hart, 2001b)

\begin{tabular}{|c|c|c|c|c|c|}
\hline & T-type & C-type & Y-type & R-type & P-type \\
\hline Diameter of oil droplet $(\mu \mathrm{m})$ & Very small (1-2) & Small (2-3) & Medium (3-3.5) & Medium (3-3.5) & Large (3.5-4.5) \\
\hline \multicolumn{6}{|l|}{ Appearance } \\
\hline Bright field illumination & Bright blue & $\begin{array}{l}\text { Colorless to } \\
\text { pale blue }\end{array}$ & $\begin{array}{l}\text { Golden yellow } \\
\text { to orange }\end{array}$ & Bright red & $\begin{array}{c}\text { Golden yellow to } \\
\text { orange }\end{array}$ \\
\hline Epifluorescence illumination & $\begin{array}{l}\text { Bright blue } \\
\text { disappears }\end{array}$ & $\begin{array}{l}\text { Bright bluish white } \\
\text { or bluish green }\end{array}$ & Dark tan & Black & $\begin{array}{l}\text { Dull cream to } \\
\text { light cream }\end{array}$ \\
\hline
\end{tabular}

Our results suggest that the cheek, crown and neck have the highest values of chromatic and achromatic contrast and thus may be involved in visual signaling. This agrees with empirical evidence showing that Canada geese have specific head and neck movement patterns to exhibit their cheeks during social displays (Akesson and Raveling, 1982). For instance, head tossing consists of the vertical flicking of the head by stationary individuals to indicate the direction of locomotion that follows where the bill points (Black and Barrow, 1985). Head pumping consists of the lowering and raising of the head in a vertical plane, which is performed when family members approach at a distance (Black and Barrow, 1985). Females perform head pumping towards goslings by placing their heads close to the ground to bring the goslings together and indicate the direction of movement. These behaviors use a highly salient signal (e.g. cheek) to synchronize movements among family members and facilitate flock cohesion (Raveling, 1969; Black and Barrow, 1985).

Another plumage region with high achromatic contrast was the upper tail covert, which is a white area above the rectrices (Fig. 1A). This flash mark, as well as the crown and cheek, may be used in flight to enhance flock cohesion (Beauchamp and Heeb, 2001). Canada geese in a non-planar V-shaped flying formation (Badgerow, 1988) may be able to establish the position of flock mates with the oblique visual streak by tracking these salient parts of the plumage. For example, the ventro-temporal portion of the visual streak would project up and in front of the animal, in the direction of the tail flash mark of a conspecific flying ahead. The dorso-nasal part of the visual streak would project downwards, in the direction of the cheek and crown of a conspecific flying towards the rear. Although the $\mathrm{V}$-shaped flying formation has been implicated in an increased ability to visualize flock mates (O'Malley and Evans, 1982; Heppner et al., 1985; Bajec and Heppner, 2009), our results suggest how the retinal configuration could match the position of flock mates in a non-planar flying formation to enhance the gathering of high quality visual information.

The distribution of cone photoreceptors in other terrestrial vertebrates that live in open habitats is characterized by the presence of a horizontal visual streak (Ahnelt et al., 2006; Schiviz et al., 2008). This visual streak is generally abundant in MWS or
LWS cones $(\mathrm{M} / \mathrm{L})$ associated with visual resolution (examples in Fig. 6), whereas SWS cones (S) may match this distribution or more generally may be prevalent in other regions of the retina (see Fig. 6). Our results show that the Canada goose visual system has features that make it rather different from that of other vertebrates living in open habitats by having an oblique visual streak with a high density of all cone photoreceptor types. Therefore, the visual world of the Canada goose consists of a wide lateral visual field with moderately sized binocular areas (Fernández-Juricic et al., 2011) subtended by a visual streak that is the retinal center of chromatic and achromatic vision. The position of this peculiar visual streak enhances visual performance from the sky and the ground simultaneously or along the horizon, depending on the position of the head. Ours is the first study to characterize the sensitivity and retinal distribution of cone photoreceptors in a bird species with a visual streak. Future studies should determine whether similar visual system configurations are present in other open-habitat birds and, if so, the ecological conditions favoring their evolution.

\section{APPENDIX}

\section{Criteria to determine differences between oil droplet types}

Generally, we followed criteria from Hart (Hart, 2001b), with slight modifications for the Canada goose retina, to differentiate oil droplets associated with different types of single and double cones: T-type (VS single cone), C-type (SWS single cone), Y-type (MWS single cone), R-type (LWS single cone) and P-type (double cone). The criteria used are presented in Table A1 and examples of the different oil droplets are shown in Fig. A1.

\section{ACKNOWLEDGEMENTS}

We thank Patricia Peng and the staff at the Providence Wildlife Rehabilitation Center for their help.

\section{FUNDING}

This project was partially funded by the US Department of Agriculture, Animal and Plant Health Inspection Service, Wildlife Services, National Wildlife Research Center and the US Federal Aviation Administration under Interagency Agreement DTFACT-09-X-90001. Additional funding was provided by Purdue University.
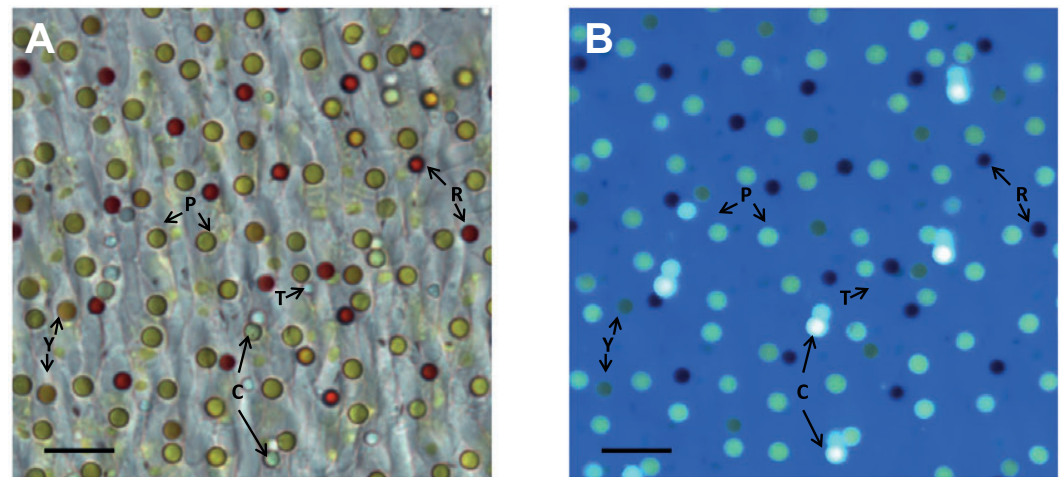

Fig. A1. Images of the Canada goose retina showing different oil droplet types in the photoreceptor layer under (A) brightfield and (B) epifluorescence microscope lighting. Scale bar, $14 \mu \mathrm{m}$. T, C, Y, R and P refer to oil droplet types in the ultraviolet-sensitive (UVS) cone, SWS cone, MWS cone, LWS cone, and the principal member of the double cone pair, respectively. 


\section{REFERENCES}

Ahnelt, P. K. and Kolb, H. (2000). The mammalian photoreceptor mosaic-adaptive design. Prog. Retin. Eye Res. 19, 711-777.

Ahnelt, P. K., Schubert, C., Kübber-Heiss, A., Schiviz, A. and Anger, E. (2006). Independent variation of retinal $\mathrm{S}$ and $\mathrm{M}$ cone photoreceptor topographies: a survey of four families of mammals. Vis. Neurosci. 23, 429-435.

Akesson, T. R. and Raveling, D. G. (1982). Behaviors associated with seasonal reproduction and long-term monogamy in Canada geese. Condor 84, 188-196.

Badgerow, J. P. (1988). An analysis of function in the formation flight of Canada geese. Auk 105, 749-755.

Bajec, I. L. and Heppner, F. H. (2009). Organized flight in birds. Anim. Behav. 78, 777-789.

Beauchamp, G. and Heeb, P. (2001). Social foraging and the evolution of white plumage. Evol. Ecol. Res. 3, 703-720.

Black, J. M. and Barrow, J. H., Jr (1985). Visual signaling in Canada geese for the coordination of family units. Wildfow/ $36,35-41$

Bowmaker, J. K. (1977). The visual pigments, oil droplets and spectral sensitivity of the pigeon. Vision Res. 17, 1129-1138.

Bowmaker, J. K., Heath, L. A., Wilkie, S. E. and Hunt, D. M. (1997). Visual pigments and oil droplets from six classes of photoreceptor in the retinas of birds. Vision Res. 37, 2183-2194.

Boycott, B. and Wässle, H. (1999). Parallel processing in the mammalian retina: the Proctor Lecture. Invest. Ophthalmol. Vis. Sci. 40, 1313-1327.

Brown, P. K. and Wald, G. (1964). Visual pigments in single rods and cones of the human retina. Science $144,45-46$

Calderone, J. B., Reese, B. E. and Jacobs, G. H. (2003). Topography of photoreceptors and retinal ganglion cells in the spotted hyena (Crocuta crocuta). Brain Behav. Evol. 62, 182-192.

Cohen, A. I. (1963). The fine structure of the visual receptors of the pigeon. Exp. Eye Res. 2, 88-97.

Collin, S. P. (1999). Behavioural ecology and retinal cell topography. In Adaptive Mechanisms in the Ecology of Vision (ed. S. N. Archer, M. B. S. Djamgoz, E. R. Loew, J. C. Partridge and S. Vallerga), pp. 509-535. Dordrecht, The Netherlands: Kluwer Academic Publishers.

Dowling, J. E. (2012). The Retina: An Approachable Part of the Brain. Cambridge, MA: Belknap Press of Harvard University Press.

Endler, J. A. and Mielke, P. W., Jr (2005). Comparing entire colour patterns as birds see them. Biol. J. Linn. Soc. Lond. 86, 405-431.

Fernández-Juricic, E. (2012). Sensory basis of vigilance behavior in birds: synthesis and future prospects. Behav. Processes 89, 143-152.

Fernández-Juricic, E., Moore, B. A., Doppler, M., Freeman, J., Blackwell, B. F., Lima, S. L. and DeVault, T. L. (2011). Testing the terrain hypothesis: Canada geese see their world laterally and obliquely. Brain Behav. Evol. 77, 147-158.

Fite, K. V. and Rosenfield-Wessels, S. (1975). A comparative study of deep avian foveas. Brain Behav. Evol. 12, 97-115.

Goldsmith, T. H. and Butler, B. K. (2005). Color vision of the budgerigar (Melopsittacus undulatus): hue matches, tetrachromacy, and intensity discrimination. J. Comp. Physiol. A 191, 933-951.

Goldsmith, T. H., Collins, J. S. and Licht, S. (1984). The cone oil droplets of avian retinas. Vision Res. 24, 1661-1671.

Gomez, D. (2006). AVICOL, a program to analyse spectrometric data. Free program available at http://sites.google.com/site/avicolprogram/ or from the author at dodogomez@yahoo.fr.

Gomez, D. and Théry, M. (2004). Influence of ambient light on the evolution of color signals: comparative analysis of a Neotropical rainforest bird community. Ecol. Lett. 7, 279-284.

Göth, A. and Evans, C. S. (2004). Social responses without early experience: Australian brush-turkey chicks use specific visual cues to aggregate with conspecifics. J. Exp. Biol. 207, 2199-2208.

Govardovskii, V. I., Fyhrquist, N., Reuter, T., Kuzmin, D. G. and Donner, K. (2000) In search of the visual pigment template. Vis. Neurosci. 17, 509-528.

Hart, N. S. (2001a). The visual ecology of avian photoreceptors. Prog. Retin. Eye Res. 20, 675-703.

Hart, N. S. (2001b). Variations in cone photoreceptor abundance and the visual ecology of birds. J. Comp. Physiol. A 187, 685-697.

Hart, N. S. (2002). Vision in the peafowl (Aves: Pavo cristatus). J. Exp. Biol. 205, 3925-3935.

Hart, N. S. and Hunt, D. M. (2007). Avian visual pigments: characteristics, spectral tuning, and evolution. Am. Nat. 169 Suppl. 1, S7-S26.

Hart, N. S. and Vorobyev, M. (2005). Modelling oil droplet absorption spectra and spectral sensitivities of bird cone photoreceptors. J. Comp. Physiol. A 191, 381-392.

Heppner, F. H., Convissar, J. L., Moonan, D. E., Jr and Anderson, J. G. T. (1985) Visual angle and formation flight in Canada geese (Branta canadensis). Auk 102, 195-198.

Hughes, A. (1977). The topography of vision in mammals of contrasting life style: comparative optics and retinal organization. In The Visual System in Vertebrates (ed. F. Crescitelli), pp. 615-756. New York, NY: Springer-Verlag.

Hunt, D. M., Carvalho, L. S., Cowing, J. A. and Davies, W. L. (2009). Evolution and spectral tuning of visual pigments in birds and mammals. Phil. Trans. R. Soc. B 364, 2941-2955

Jane, S. D. and Bowmaker, J. K. (1988). Tetrachromatic colour vision in the duck (Anas platyrhynchos): microspectrophotometry of visual pigments and oil droplets. $J$. Comp. Physiol. A 162, 225-235.

Land, M. F. and Nilsson, D.-E. (2002). Animal Eyes. Oxford: Oxford University Press Levine, J. S. and MacNichol, E. F., Jr (1985). Microspectrophotometry of primate photoreceptors: art, artifact and analysis. In The Visual System (ed. A. Fein and J. S. Levine), pp. 73-88. New York: Liss.
Liebman, P. A. (1972). Microspectrophotometry of Photoreceptors. In Handbook of Sensory Physiology, Vol. 2 (ed. H. J. A. Dartnall), pp. 481-528. Berlin, Germany: Springer.

Lipetz, L. E. (1984). A new method for determining peak absorbance of dense pigment samples and its application to the cone oil droplets of Emydoidea blandingii. Vision Res. 24, 597-604.

Litherland, L. and Collin, S. P. (2008). Comparative visual function in elasmobranchs: spatial arrangement and ecological correlates of photoreceptor and ganglion cell distributions. Vis. Neurosci. 25, 549-561.

Loew, E. R. and Stauble, M. (1988-1992). MSP control and analysis program [computer software]. Ithaca: New York State College of Veterinary Medicine.

McFarland, W. N. and Loew, E. R. (1994). Ultraviolet visual pigments in marine fishes of the family pomacentridae. Vision Res. 34, 1393-1396.

Meyer, D. B., Cooper, T. G. and Gernez, C. (1965). Retinal oil droplets. In The Structure of the Eye: /l Symposium (ed. J. W. Rohen), pp. 521-533. Stuttgart, Germany: Schattauer.

Meyer, D. B. C. (1977). The avian eye and its adaptations. In The Visual System of Vertebrates, Handbook of Sensory Physiology, Vol. 5 (ed. F. Crescitelli), pp. 549612. New York, NY: Springer.

Montgomerie, R. (2006). Analyzing colors. In Bird Coloration: Mechanisms and Measurements (ed. G. E. Hill and K. J. McGraw). Cambridge, MA: Harvard University Press.

Mowbray, T. B., Ely, C. R., Sedinger, J. S. and Trost, R. E. (2002). Canada Goose (Branta canadensis), The Birds of North America Online (ed. A. Poole). Ithaca, NY: Cornell Lab of Ornithology (retrieved from the Birds of North America online: http://bna.birds.cornell.edu.bnaproxy.birds.cornell.edu/bna/species/682).

Müller, B. and Peichl, L. (1989). Topography of cones and rods in the tree shrew retina. J. Comp. Neurol. 282, 581-594.

Ödeen, A. and Håstad, O. (2003). Complex distribution of avian color vision systems revealed by sequencing the SWS1 opsin from total DNA. Mol. Biol. Evol. 20, 855861.

Ödeen, A., Håstad, O. and Alström, P. (2011). Evolution of ultraviolet vision in the largest avian radiation - the passerines. BMC Evol. Biol. 11, 313.

O'Malley, J. B. E. and Evans, R. M. (1982). Flock formation in white pelicans. Can. J. Zool. 60, 1024-1031.

Osorio, D., Miklosi, A. and Gonda, Z. (1999a). Visual ecology and perception of coloration patterns by domestic chicks. Evol. Ecol. 13, 673-689.

Osorio, D., Vorobyev, M. and Jones, C. D. (1999b). Colour vision in chicks. J. Exp. Biol. 202, 2951-2959.

Partridge, C. (1989). The visual ecology of avian cone oil droplets. J. Comp. Physiol. A 165, 415-426.

Querubin, A., Lee, H. R., Provis, J. M. and O'Brien, K. M. B. (2009). Photoreceptor and ganglion cell topographies correlate with information convergence and high acuity regions in the adult pigeon (Columba livia) retina. J. Comp. Neurol. 517, 711722.

Rahman, M. L., Aoyama, M. and Sugita, S. (2007a). Topography of retinal photoreceptor cells in the jungle crow (Corvus macrorhynchos) with emphasis on the distribution of oil droplets. Ornitholog. Sci. 6, 29-38.

Rahman, M. L., Aoyama, M. and Sugita, S. (2007b). Number and density of retina photoreceptor cells with emphasis on oil droplet distribution in the mallard duck (Anas platyrhynchos var. domesticus). Anim. Sci. J. 78, 639-649.

Raveling, D. G. (1969). Preflight and flight behavior of Canada Geese. Auk 86, 671681.

Raveling, D. G. (1970). Dominance relationships and agonistic behavior of Canada geese in winter. Behaviour 37, 291-318.

Rubene, D., Håstad, O., Tauson, R., Wall, H. and Odeen, A. (2010). The presence of UV wavelengths improves the temporal resolution of the avian visual system. J. Exp. Biol. 213, 3357-3363.

Sandre, S. L., Stevens, M. and Mappes, J. (2010). The effect of predator appetite, prey warning coloration and luminance on predator foraging decisions. Behaviour 147, 1121-1143.

Schiviz, A. N., Ruf, T., Kuebber-Heiss, A., Schubert, C. and Ahnelt, P. K. (2008). Retinal cone topography of artiodactyl mammals: influence of body height and habitat. J. Comp. Neurol. 507, 1336-1350.

Shinozaki, A., Hosaka, Y., Imagawa, T. and Uehara, M. (2010). Topography of ganglion cells and photoreceptors in the sheep retina. J. Comp. Neurol. 518, 23052315.

Siddiqi, A., Cronin, T. W., Loew, E. R., Vorobyev, M. and Summers, K. (2004) Interspecific and intraspecific views of color signals in the strawberry poison frog Dendrobates pumilio. J. Exp. Biol. 207, 2471-2485.

Stone, J. (1981). The Wholemount Handbook: A Guide to the Preparation and Analysis of Retinal Wholemounts. Sydney, Australia: Maitland.

Ullmann, J. F. P., Moore, B. A., Temple, S. E., Fernández-Juricic, E. and Collin, S. P. (2012). The retinal wholemount technique: a window to understanding the brain and behaviour. Brain Behav. Evol. 79, 26-44.

von Campenhausen, M. and Kirschfeld, K. (1998). Spectral sensitivity of the accessory optic system of the pigeon. J. Comp. Physiol. A 183, 1-6.

Vorobyev, M. and Osorio, D. (1998). Receptor noise as a determinant of colour thresholds. Proc. Biol. Sci. 265, 351-358.

Warrant, E. J. (1999). Seeing better at night: life style, eye design and the optimum strategy of spatial and temporal summation. Vision Res. 39, 1611-1630.

Wikler, K. C. and Rakic, P. (1990). Distribution of photoreceptor subtypes in the retina of diurnal and nocturnal primates. J. Neurosci. 10, 3390-3401.

Wood, C. A. (1917). The Fundus Oculi of Birds Especially as Viewed by the Ophthalmoscope, pp. 1-180. Chicago, IL: The Lakeside Press. 